\title{
A novel endoscopic assessment of the gastroesophageal junction for the prediction of gastroesophageal reflux disease: a pilot study
}

\section{(ㄷ)(1) $\Theta$}

\author{
Authors \\ Haruo Ikeda, Manabu Onimaru, Yuto Shimamura \\ Institution \\ Digestive Diseases Center, Showa University Koto Toyosu \\ Hospital, Tokyo 135-8577, Japan \\ submitted 12.5 .2019 \\ accepted after revision 9.7.2019 \\ Bibliography \\ DOI https://doi.org/10.1055/a-0990-9737 | \\ Endoscopy International Open 2019; 07: E1468-E1473 \\ (c) Georg Thieme Verlag KG Stuttgart · New York \\ elSSN 2196-9736 \\ Corresponding author \\ Yusuke Fujiyoshi, MD, Digestive Diseases Center, Showa \\ University Koto Toyosu Hospital, 5-1-38 Toyosu, Koto-ku, \\ Tokyo 135-8577, Japan \\ Fax: +81-3-62046396 \\ yusukefujiyoshi@yahoo.co.jp
}

Haruhiro Inoue, Yusuke Fujiyoshi, Mary Raina Angeli Abad, Enrique Rodriguez de Santiago, Kazuya Sumi, Yugo Iwaya,

\section{ABSTRACT}

Background and aim Hiatal hernia and lower esophageal sphincter (LES) dysfunction play major roles in gastroesophageal reflux disease (GERD) pathogenesis. We developed a novel endoscopic assessment to evaluate the gastroesophageal junction (GEJ). This study aims to evaluate the feasibility of this method for the diagnostic prediction of GERD.

Methods A retrospective analysis of patients with GERD symptoms who underwent gastroscopy and esophageal
$\mathrm{pH}$-impedance monitoring was conducted. The novel assessment evaluated the following in retroflex view: 1) Cardiac Opening (CO): diameter of the opening of the cardia, 2) Sliding Hernia (SH): length from the diaphragmatic crus to the squamocolumnar junction, 3) Scope Holding Time\% (SHT\%): the percentage of time that the Scope Holding Sign (SHS) was observed out of 30 seconds. The SHS is defined as the lower esophagus holding the endoscope under excessive insufflation. The results of this assessment and that of $\mathrm{pH}$-impedance monitoring were compared.

Results In total, 61 patients (mean age \pm SD, $54.1 \pm 16.4$ years, 32 males) were enrolled. $\mathrm{CO}$ and $\mathrm{SH}$ were significantly correlated with acid exposure time (AET) $(\rho=0.36, P=$ 0.005 , and $\rho=0.36, P=0.004)$. The optimal cutoff of CO for $\mathrm{AET}>6 \%$ was $3 \mathrm{~cm}$ (Sensitivity $=72.4 \%$, Specificity= $46.9 \%, A \cup C=0.64$ ) and that of $\mathrm{SH}$ was $2 \mathrm{~cm}$ (Sensitivity= $55.2 \%$, Specificity $=75.0 \%, A \cup C=0.70)$. When the population was stratified according to this cutoff, patients with $\mathrm{CO}>3 \mathrm{~cm}$ and those with $\mathrm{SH}>2 \mathrm{~cm}$ presented higher AET ( 15.1 vs $4.1 \%, P=0.037$, and 23.0 vs $3.6 \%, P=0.026$ ). Optimal cutoff of SHT\% for the number of all reflux episodes $>80$ was $75 \%$ (Sensitivity $=81.8 \%$, Specificity $=$ $54.6 \%, A U C=0.67)$. Patients with $\mathrm{SHT} \%<75 \%$ presented a higher number of all reflux episodes ( 88 vs $65, P=0.014$ ). Sensitivity, specificity, and accuracy of SHT\% $<75 \%$ for all reflux episodes $>80$ were $81.8 \%$ (95\%Cl: $67.7-91.8)$, $54.5 \%$ (95\%Cl: 40.4-64.5), and 68.2\% (95\%Cl: $54.0-$ 78.1).

Conclusion This novel endoscopic assessment of GEJ significantly predicted the presence of GERD and merits further testing in future studies.

\section{Introduction}

Gastroesophageal reflux disease (GERD) is a common gastrointestinal disorder defined as the presence of symptoms or complications resulting from the retrograde flow of gastric contents into the esophagus [1]. Various mechanisms exist in the pathophysiology of GERD, including morphological factors such as a hiatal hernia, and functional factors such as incompetence of the lower esophageal sphincter (LES), impaired esophageal peristalsis and clearance [2].

Among the morphological factors, hiatal hernia $(\mathrm{HH})$ has a high prevalence and is deemed to play a major role in GERD pathogenesis [3]. $\mathrm{HH}$ is endoscopically diagnosed when the separation between the squamocolumnar junction (SCJ) and the constriction of the stomach through the hiatus is greater than $2 \mathrm{~cm}[4]$. This diagnosis is established by forward view of the 
gastroesophageal junction (GEJ); however, it can be influenced by the degree of insufflation, respiration phase, retching and belching, which hinder the standardization of endoscopic assessment $[3,4]$. The Hill grade classification is used to assess the gastroesophageal flap valve function and has proven to be able to predict the presence of acid reflux [5]; however, this classification does not consider some endoscopic features that may enhance GERD prediction ability.

Therefore, we suggest a novel endoscopic assessment method to evaluate the GEJ morphologically and functionally. This study aims to evaluate the feasibility of the new endoscopic assessment for the diagnostic prediction of GERD.

\section{Materials and methods}

\section{Study population}

This is a retrospective, single-center study from a prospectively collected database performed between April 2016 and July 2018 at Showa University Koto Toyosu Hospital, Tokyo, Japan. Patients experiencing major GERD symptoms (heartburn, chest pain or belching) who underwent upper gastrointestinal endoscopy and esophageal multichannel intraluminal impedance-pH monitoring ( $\mathrm{pH}$-impedance monitoring) (ZepHr, Sandhill Scientific, Inc., Colorado, United States) were included. GERD diagnosis was based on $\mathrm{pH}$-impedance monitoring. Patients with prior laparoscopic Nissen and Toupet fundoplication or Anti-Reflux Mucosectomy (ARMS) [6] were excluded. Proton pump inhibitors (PPIs) were suspended 7 days before the $\mathrm{pH}$-impedance study.

\section{Endoscopic assessment of the gastroesophageal junction}

Endoscopic examinations were carried out using high definition endoscopes (GIF-H260Z/GIF-H290Z, Olympus Medical Systems Corp., Tokyo, Japan) with outer diameters of $10.8 \mathrm{~mm}$ and $9.9 \mathrm{~mm}$, respectively. Intravenous propofol was used as sedation. Endoscopic examinations were performed by boardcertified fellows of the Japan Gastroenterological Endoscopy Society.

The novel assessment method of the GEJ was performed in retroflex view under excessive and high-flow insufflation (MAJ1741, Olympus Medical Systems Corp., Tokyo, Japan) until the folds of the greater curvature flattened and maximum GEJ opening was observed. We evaluated: 1) Cardiac Opening (CO): the diameter of the opening of the cardia (cm), 2) Sliding Hernia (SH): the length from the diaphragmatic crus to the $\mathrm{SC}$ (cm) ( Fig. 1), 3) Scope Holding Sign (SHS): lower esophagus holding the endoscope ( $\triangleright$ Fig. 1, $>$ Fig. 2). Based on SHS, Scope Holding Time\% (SHT\%) is defined as the percentage of time that the SHS was observed out of 30 seconds in retroflex view. For patients who experienced belching before the greater curvature folds flattened upon insufflation, SHT\% was measured before belching while under maximum insufflation. Length was measured using the scope diameter as a reference, which was approximately $1 \mathrm{~cm}$. Still endoscopic images from endoscopic videos were reviewed by three endoscopists to assess $\mathrm{CO}$ and
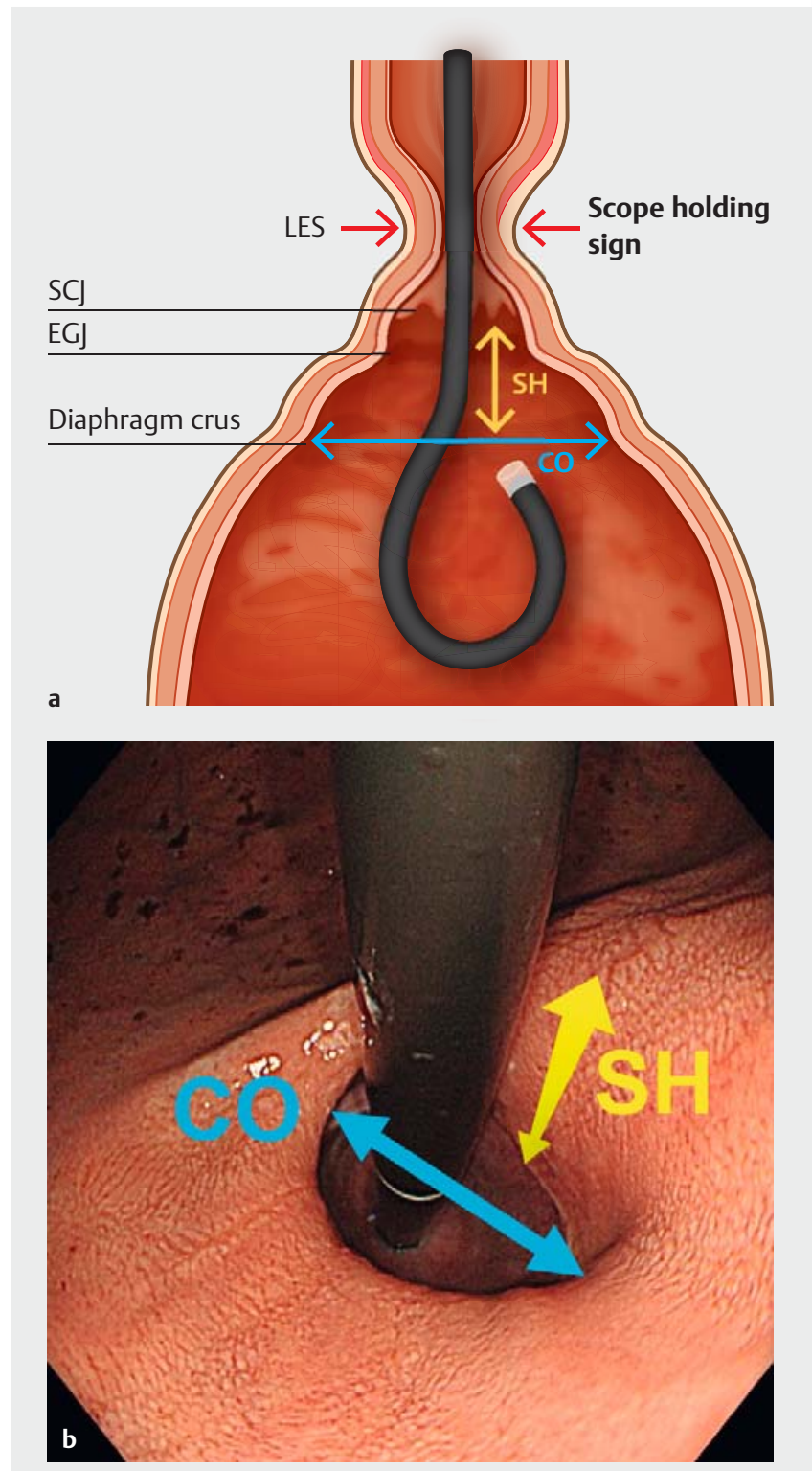

- Fig. 1 CO, SH, and Scope Holding Sign: Schema and endoscopic image of hiatal hernia showing cardiac opening (CO), sliding hernia (SH), Scope Holding Sign, lower esophageal sphincter (LES), squamocolumnar junction (SCJ), and gastroesophageal junction (GEJ).

SH. For SHT\%, endoscopic videos were analyzed. An agreement was made to show concordance.

The results of this assessment method and that of $\mathrm{pH}$-impedance monitoring were compared. The primary outcome was acid exposure time (AET), and secondary outcomes were DeMeester composite score, the number of all reflux (liquid, gas or mixed, and acid or non-acid) episodes, and the number of proximal reflux episodes. AET is the percent time with $\mathrm{pH}<4$, and $\mathrm{AET}$ of more than $6 \%$, and the number of all reflux episodes $>80$ were considered to be definitively abnormal based on the 2018 Lyon Consensus [7]. 


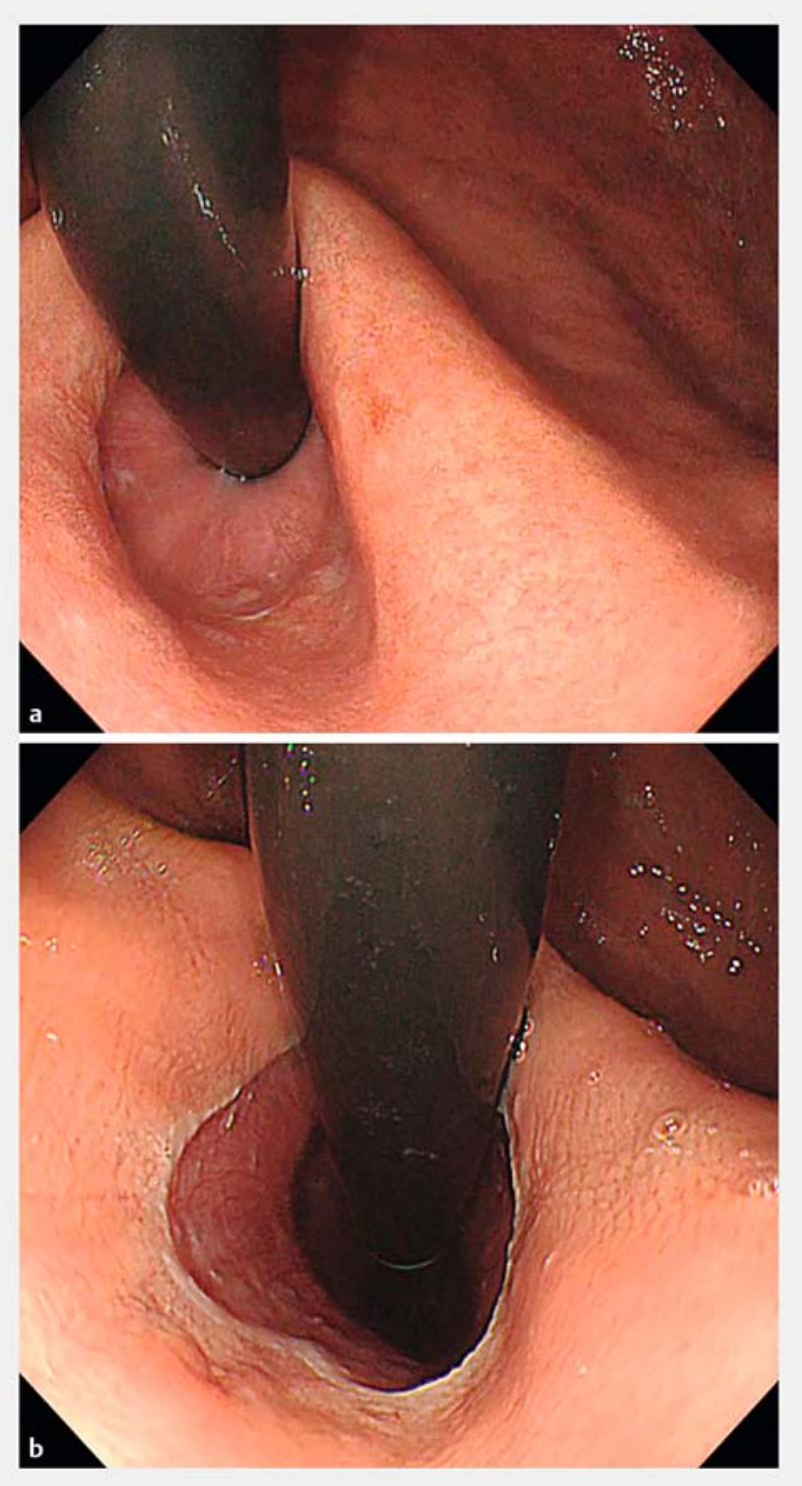

- Fig. 2 Scope Holding Sign positive and negative: Endoscopic image of Scope Holding Sign positive (a) and negative (b) during excessive and high-flow insufflation in retroflex view.

\section{Statistical analysis}

Mean, standard deviation (SD), median, and range were calculated for continuous variables, and frequency counts and percentages for categorical data. Chi-squared and Fisher's exact tests were used for categorical data. The Spearman correlation coefficient was used to test the correlation between the quantitative variables. Optimal cutoff points for $\mathrm{CO}$ and $\mathrm{SH}$ values were calculated with ROC curve analyses to maximize sensitivity and specificity, using the Youden J index. All analyses were two-tailed, and $P$ values less than 0.05 were considered statistically significant. All statistical analyses were conducted using JMP 14 (SAS Institute Inc., Cary, North Carolina, United States).
- Table 1 Patient characteristics $(n=61)$.

\begin{tabular}{|l|l|}
\hline Variable & Value \\
\hline Age, mean \pm SD, years & $54.1 \pm 16.4$ \\
\hline Male gender, $\mathrm{n}(\%)$ & $32(52.4 \%)$ \\
\hline BMI, mean \pm SD, $\mathrm{kg} / \mathrm{m}^{2}$ & $21.9 \pm 4.0$ \\
\hline \hline Los Angeles Classification (esophagitis), $\mathrm{n}(\%)$ & \\
\hline - Grade N & $43(70.5 \%)$ \\
\hline - Grade A & $6(9.8 \%)$ \\
\hline - Grade B & $6(9.8 \%)$ \\
\hline - Grade C & $5(8.2 \%)$ \\
\hline - Grade D & $1(1.6 \%)$ \\
\hline GERD symptoms, $\mathrm{n}(\%)$ & $37(60.7 \%)$ \\
\hline - Heartburn & $52(85.2 \%)$ \\
\hline - Chest pain & $27(44.3 \%)$ \\
\hline - Belching & \\
\hline $\begin{array}{l}\text { SD, standard deviation; BMI, body mass index; GERD, gastroesophageal } \\
\text { reflux disease }\end{array}$ & \\
\hline
\end{tabular}

\section{Ethical considerations}

The study protocol adhered to the principles of the Declaration of Helsinki and was approved by the Institutional Review Board (IRB) of Showa University Koto Toyosu Hospital (IRB Registration No: 18T7054). Written informed consent for the upper gastrointestinal endoscopy was obtained from all participants. In accordance with the IRB, individual informed consent for inclusion in this study was not required. The research outline was appropriately notified on the website of Showa University Koto Toyosu Hospital and an appropriate refusal opportunity was given for the use of medical record information.

\section{Results}

A total of 110 patients were screened. Among these, laparoscopic Nissen fundoplication $(n=8)$, laparoscopic Toupet $(n=$ $7)$, and ARMS ( $n=34)$ were excluded. Consequently, a total of 61 patients were finally included. Mean age $( \pm$ SD) was $54.1 \pm$ 16.4 years, with 32 males (52.4\%). Population characteristics are presented in $>$ Table 1.

\section{Cardiac opening}

CO was significantly correlated with AET $(\rho=0.36, P=0.005)$ and DeMeester composite score $(\rho=0.35, P=0.006)$. There was no correlation between $\mathrm{CO}$ and the number of all reflux episodes $(\rho=0.04, P=0.78)$ and proximal reflux episodes $(\rho=$ $-0.05, P=0.72)$.

The optimal cutoff of CO for AET $>6 \%$ was $3 \mathrm{~cm}$ (Sensitivity= $72.4 \%$, Specificity $=46.9 \%$, Area under the ROC curve (AUROC) $=0.64)$. When the population was stratified according to this cutoff, patients with $\mathrm{CO}>3 \mathrm{~cm}$ presented higher AET $(P=$ $0.037)$ and DeMeester composite score $(P=0.075)$, as shown 
- Table2 Statistical analysis for CO.

\begin{tabular}{|l|l|l|l|}
\hline & $\begin{array}{l}\mathbf{C O} \leq \mathbf{3} \mathbf{c m} \\
(\mathbf{n = 4 6 )}\end{array}$ & $\begin{array}{l}\mathbf{C O}>\mathbf{3} \mathbf{c m} \\
(\mathbf{n = 1 5 )}\end{array}$ & P value \\
\hline AET\% & $\begin{array}{l}4.1 \\
(1.1-12.3)\end{array}$ & $\begin{array}{l}15.1 \\
(2.1-36.5)\end{array}$ & 0.037 \\
\hline $\begin{array}{l}\text { DeMeester compo- } \\
\text { site score }\end{array}$ & $\begin{array}{l}14.3 \\
(5.1-41.9)\end{array}$ & $\begin{array}{l}48.8 \\
(8.2-109.1)\end{array}$ & 0.075 \\
\hline All reflux episodes & 80 & 78 & 0.48 \\
\hline $\begin{array}{l}\text { Proximal reflux epi- } \\
\text { sodes }\end{array}$ & $\begin{array}{l}(55.3-112) \\
(19.5-48)\end{array}$ & $\begin{array}{l}(61-119) \\
(22-46)\end{array}$ & 0.22 \\
\hline
\end{tabular}

AET, acid exposure time; $\mathrm{CO}$, cardiac opening.

- Table 3 Statistical analysis for SH.

\begin{tabular}{|l|l|l|l|}
\hline & $\begin{array}{l}\mathbf{S H} \leq \mathbf{2} \mathbf{c m} \\
\mathbf{( n = 5 3 )}\end{array}$ & $\begin{array}{l}\mathbf{S H}>\mathbf{2} \mathbf{c m} \\
\mathbf{( n = 8 )}\end{array}$ & $\mathbf{P}$ value \\
\hline AET\% & 3.6 & 22.95 & 0.026 \\
\hline & $(1.1-13.7)$ & $(10.2-46.3)$ & \\
\hline $\begin{array}{l}\text { DeMeester compo- } \\
\text { site score }\end{array}$ & $\begin{array}{l}13.3 \\
(6.0-41.7)\end{array}$ & $\begin{array}{l}70.9 \\
(35.1-113.1)\end{array}$ & 0.044 \\
\hline All reflux episodes & 78 & 77 & 0.49 \\
\hline $\begin{array}{l}\text { Proximal reflux epi- } \\
\text { sodes }\end{array}$ & $\begin{array}{l}30.5 \\
(20.25-48)\end{array}$ & $\begin{array}{l}(54.5-15.25) \\
(22.25-30)\end{array}$ & 0.19 \\
\hline
\end{tabular}

AET, acid exposure time; SH, sliding hernia.

in $>$ Table 2. When the patients were divided into two groups of $\mathrm{CO}>3 \mathrm{~cm}$ and $\mathrm{CO} \leq 3 \mathrm{~cm}$, there was no statistically significant difference in age, gender, or body mass index.

\section{Sliding hernia}

Eight patients (13.1\%) had a SH of more than $2 \mathrm{~cm}$ and 53 patients $(86.9 \%)$ had a SH of $2 \mathrm{~cm}$ or less. Nine patients (14.8\%) had a $\mathrm{SH}$ of $2 \mathrm{~cm}$ or less, and a $\mathrm{CO}$ of more than $3 \mathrm{~cm}$.

$\mathrm{SH}$ was significantly correlated with AET $(\rho=0.36, P=0.004)$ and DeMeester composite score $(\rho=0.38, P=0.003)$. There was no correlation between $\mathrm{SH}$ and the number of all reflux episodes $(\rho=-0.08, P=0.55)$ and proximal reflux episodes $(\rho=-0.10, P=$ $0.43)$.

The optimal cutoff of SH for AET $>6 \%$ was $2 \mathrm{~cm}$ (Sensitivity= $55.2 \%$, Specificity $=75.0 \%$, AUROC $=0.70$ ). When the population was stratified according to this cutoff, patients with $\mathrm{SH}>$ $2 \mathrm{~cm}$ presented higher AET $(P=0.026)$ and DeMeester composite score $(P=0.044)$, as shown in $>$ Table 3 . When the patients were divided into two groups of $\mathrm{SH}>2 \mathrm{~cm}$ and $\mathrm{SH} \leq 2 \mathrm{~cm}$, there was no statistically significant difference in age, gender, or body mass index.

The distribution of $\mathrm{CO}$ and $\mathrm{SH}$ for the patients in this study is shown in - Fig. 3.
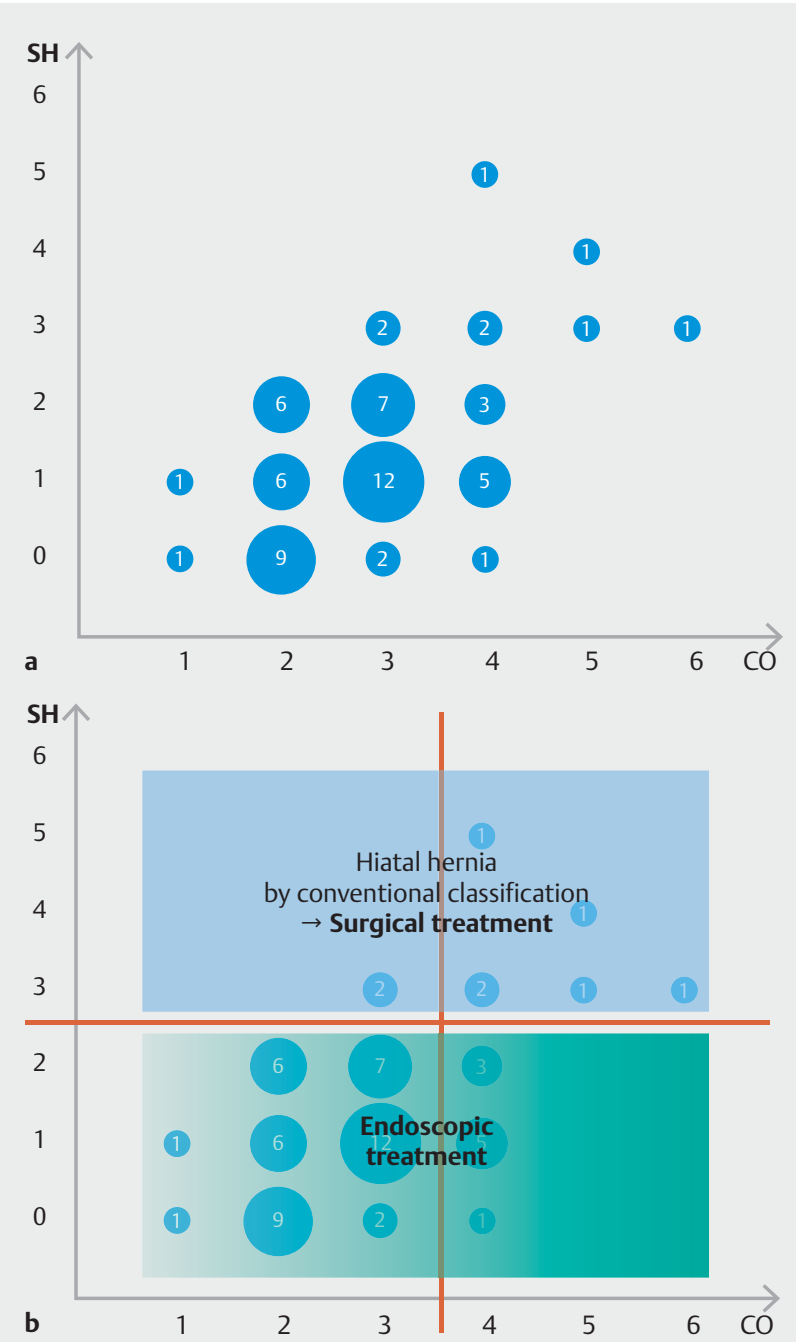

Fig. 3 Distribution of $\mathrm{CO}$ and SH: A distribution map of $\mathrm{CO}$ and SH for the patients in this study (a) showing the indication for surgical and endoscopic treatment of hiatal hernia (b).

- Table 4 Statistical analysis for SHT\%.

\begin{tabular}{|c|c|c|c|}
\hline & $\begin{array}{l}\text { SHT\% }<75 \% \\
(n=29)\end{array}$ & $\begin{array}{l}\text { SHT } \% \geq 75 \% \\
(n=16)\end{array}$ & $P$ value \\
\hline AET\% & $\begin{array}{l}4.8 \\
(2.15-21)\end{array}$ & $\begin{array}{l}1.3 \\
(0.4-17.9)\end{array}$ & 0.81 \\
\hline $\begin{array}{l}\text { DeMeester composite } \\
\text { score }\end{array}$ & $\begin{array}{l}15.6 \\
(8.6-70.9)\end{array}$ & $\begin{array}{l}6.15 \\
(2.6-55.4)\end{array}$ & 0.74 \\
\hline All reflux episodes & $\begin{array}{l}88 \\
(61.3-128.3)\end{array}$ & $\begin{array}{l}65 \\
(52.0-82.3)\end{array}$ & 0.014 \\
\hline $\begin{array}{l}\text { Proximal reflux epi- } \\
\text { sodes }\end{array}$ & $\begin{array}{l}33.5 \\
(23.5-54.5)\end{array}$ & $\begin{array}{l}21 \\
(14.8-24.0)\end{array}$ & 0.0098 \\
\hline
\end{tabular}

AET, acid exposure time; SHT\%, scope holding time\%. 
- Table 5 Diagnostic performance of SHT\% $<75 \%$.

\begin{tabular}{|c|c|c|c|c|c|c|}
\hline $\begin{array}{l}\text { Specificity (\%) } \\
(95 \% \mathrm{Cl})\end{array}$ & $\begin{array}{l}\text { Sensitivity (\%) } \\
(95 \% \mathrm{Cl})\end{array}$ & $\begin{array}{l}\text { PPV (\%) } \\
\text { (95\%Cl) }\end{array}$ & $\begin{array}{l}\text { NPV (\%) } \\
(95 \% \mathrm{Cl})\end{array}$ & $\mathrm{LR}+(95 \% \mathrm{Cl})$ & LR - (95\%Cl) & $\begin{array}{l}\text { Accuracy (\%) } \\
(95 \% \mathrm{Cl})\end{array}$ \\
\hline $\begin{array}{l}54.5 \\
(40.4-64.5)\end{array}$ & $\begin{array}{l}81.8 \\
(67.7-91.8)\end{array}$ & $\begin{array}{l}64.3 \\
(53.2-72.1)\end{array}$ & $\begin{array}{l}75.0 \\
(55.5-88.7)\end{array}$ & $\begin{array}{l}1.80 \\
(1.14-2.56)\end{array}$ & $\begin{array}{l}0.33 \\
(0.13-0.80)\end{array}$ & $\begin{array}{l}68.2 \\
(54.0-78.1)\end{array}$ \\
\hline
\end{tabular}

$\mathrm{Cl}$, confidence interval; PPV, positive predictive value; NPV, negative predictive value; LR, likelihood ratio.

\section{Scope holding time \%}

There was no significant correlation between SHT\% and AET ( $\rho$ $=-0.2, P=0.17)$, DeMeester composite score $(\rho=-0.23, P=$ $0.12)$, the number of all reflux episodes $(\rho=-0.22, P=0.14)$, and the number of proximal reflux episodes $(\rho=-0.24, P=$ $0.12)$.

The optimal cutoff of SHT\% for the number of all reflux episodes $>80$ was $75 \%$ (Sensitivity $=81.8 \%$, Specificity $=54.6 \%$, AUROC $=0.67$ ). When the population was stratified into SHT $\% \geq 75 \%$ and SHT\% $<75 \%$, patients with SHT\%<75\% presented a higher number of all reflux episodes $(P=0.014)$ and proximal reflux episodes $(P=0.0098)$, as shown in $>$ Table 4 . The sensitivity, specificity, and accuracy of SHT\% $<75 \%$ for all reflux episodes $>80$ are summarized in $>$ Table 5 .

\section{Discussion}

In this study, we performed a novel endoscopic assessment of the GEJ and the LES function using $\mathrm{CO}, \mathrm{SH}$, and $\mathrm{SHT}$ \% to enhance the diagnostic prediction of GERD. The relationship between the degree of $\mathrm{CO}, \mathrm{SH}, \mathrm{SHT} \%$, and gastroesophageal reflux assessed by $\mathrm{pH}$-impedance monitoring was systematically evaluated and a new assessment method is proposed. Our main results were that patients with $\mathrm{CO}>3 \mathrm{~cm}$ or $\mathrm{SH}>2 \mathrm{~cm}$ presented higher AET and DeMeester composite score, and patients with SHT\% of less than $75 \%$ presented a higher number of all reflux episodes and proximal reflux episodes.

Previous studies have shown that an impairment of the gastroesophageal flap [5], and an increase in the cardia circumference cause an increase in the frequency of GERD [8]; however, earlier studies did not evaluate the degree of $\mathrm{SH}$ in the retroflex view, and a method of simultaneously describing the degree of $\mathrm{CO}$ and $\mathrm{SH}$ had not been accomplished. In this study, $\mathrm{CO}$ and $\mathrm{SH}$ were intended to measure the size of the $\mathrm{HH}$ horizontally and vertically. An increase in $\mathrm{CO}$ and $\mathrm{SH}$ causes an increase in the volume of $\mathrm{HH}$ and probably reflects LES incompetence, leading to a build-up of gastric acid, hence causing more acid reflux [9]. As depicted here, $\mathrm{CO}$ and SH significantly correlated with acid reflux considering $\mathrm{pH}$-impedance as the gold standard criteria.

While LES is not observed in a forward view, LES contraction is triggered upon sufficient insufflation and the state of holding the endoscope by the esophagus can be observed, which is thought to be the LES as shown in > Fig. 2. This is what we have termed the SHS.Our data showed that patients with SHT\% $<75 \%$, which is equivalent to lower SHS, presented a higher number of all reflux episodes and proximal reflux episodes. Taking into account the fact that the diagnostic per- formance of SHT\% $<75 \%$ for all reflux episodes $>80$ has high sensitivity and negative predictive value, SHT\% can be useful for excluding GERD.

Based on $\mathrm{CO}$ and $\mathrm{SH}$ parameters, we propose a distribution map as a guide to determine the treatment method for GERD. Patients who have failed medical management with acid suppression are referred as an indication for surgical treatment [10], and those with $\mathrm{SH}$ of more than $2 \mathrm{~cm}$, diagnosed as definitive $\mathrm{HH}$ in previous reports [4], are especially referred as an indication for surgical treatment such as Nissen and Toupet fundoplication [11]. In contrast, patients without $\mathrm{HH}(\mathrm{SH} \leq 2 \mathrm{~cm})$ are said to be a good indication for endoscopic therapy such as ARMS [6]. As shown in - Fig. 3, by concomitantly evaluating CO and $\mathrm{SH}$, we identify the subpopulation who may benefit from endoscopic therapy. Considering that a $\mathrm{CO}$ of more than $3 \mathrm{~cm}$ independently correlates with acid reflux, these patients may benefit more from endoscopic therapy. In our facility, the treatment method is determined by this protocol as depicted in - Fig. 3, however, further evaluation is still required.

A possible adverse event during excessive and high-flow insufflation is overextension of the mucosa. However, since we evaluate $\mathrm{CO}, \mathrm{SH}$, and $\mathrm{SHT} \%$ by retroflexion, the fornix and lesser curvature could also be observed simultaneously. If mucosal damage is noticed, insufflation can be stopped immediately. Yet, this risk seems more theoretical than real, and in our study, we did not experience any adverse events.

The limitations of this study must be acknowledged. Since this is a pilot study, the sample size is relatively small, suggesting that future studies on the same topic may be necessary involving a larger population to validate the results of this study. Since the $\mathrm{CO}$ and $\mathrm{SH}$ were measured under excessive $\mathrm{CO}_{2}$ insufflation until the folds of the greater curvature flattened, the exact amount of $\mathrm{CO}_{2}$ could not be measured. The lack of a healthy control group also poses some drawbacks, therefore, the differentiation between a control group and GERD patients could not be assessed. More so, the study population pertained to those with heartburn, chest pain, and belching only and therefore, no conclusions can be drawn about the application of this new method to those experiencing other GERD symptoms. Since $\mathrm{SH}$ is defined as the length from the diaphragmatic crus to SC], this method cannot be applied to patients with Barrett's esophagus. A number of SHT\% and SHS data were missing, since this sign was not uniformly defined during the initial cases. Finally, since manometry has not been performed in this study, the LES was not accurately evaluated. Further studies are needed to compare SHT\% in endoscopy and LES relaxation in manometry to clarify the relationship between them. 
In summary, this study demonstrated that patients with $\mathrm{CO}$ of more than $3 \mathrm{~cm}$ or $\mathrm{SH}$ of more than $2 \mathrm{~cm}$ presented higher AET, and patients with SHT\% of less than $75 \%$ presented a higher number of all reflux episodes. This systematic endoscopic evaluation, taking into account the additional morphological and functional features of the GEJ, significantly predicted the presence of GERD and deserves future validation in a larger cohort.

\section{Competing interests}

$\mathrm{H}$. Inoue is an advisor of Olympus Corporation and Top Corporation. He has also received educational grants from Olympus Corp., and Takeda Pharmaceutical Co. E. Rodriguez de Santiago is a Ramón y Cajal Health Research Institute grant holder. Y. Fujiyoshi, M.R.A. Abad, K. Sumi, Y. Iwaya, H. Ikeda, M. Onimaru, and $Y$. Shimamura have no conflicts of interest to declare.

\section{References}

[1] Vakil N, van Zanten SV, Kahrilas P et al. The Montreal definition and classification of gastroesophageal reflux disease: a global evidencebased consensus. Am J Gastroenterol 2006; 101: 1900 - 1920

[2] Tack J, Pandolfino JE. Pathophysiology of gastroesophageal reflux disease. Gastroenterology 2018; 154: 277-288

[3] Hyun J], Bak YT. Clinical significance of hiatal hernia. Gut Liver 2011; 5: $267-277$

[4] Roman S, Kahrilas PJ. The diagnosis and management of hiatus hernia. BMJ 2014; 349: g6154

[5] Hill LD, Kozarek RA, Kraemer S] et al. The gastroesophageal flap valve: in vitro and in vivo observations. Gastrointest Endosc 1996; 44: 541 547

[6] Inoue $\mathrm{H}$, Ito $\mathrm{H}$, Ikeda $\mathrm{H}$ et al. Anti-reflux mucosectomy for gastroesophageal reflux disease in the absence of hiatus hernia: a pilot study. Ann Gastroenterol 2014; 27: 346-351

[7] Gyawali CP, Kahrilas P], Savarino E et al. Modern diagnosis of GERD: the Lyon Consensus. Gut 2018; 67: 1351-1362

[8] Seltman AK, Kahrilas P], Chang EY et al. Endoscopic measurement of cardia circumference as an indicator of GERD. Gastrointest Endosc 2006; 63: $22-31$

[9] Mittal RK, Lange RC, McCallum RW. Identification and mechanism of delayed esophageal acid clearance in subjects with hiatus hernia. Gastroenterology 1987; 92: 130-135

[10] Stefanidis D, Hope WW, Kohn GP et al. Guidelines for surgical treatment of gastroesophageal reflux disease. Surg Endosc 2010; 24: $2647-2669$

[11] Kohn GP, Price RR, DeMeester SR et al. Guidelines for the management of hiatal hernia. Surg Endosc 2013; 27: 4409-4428 